\title{
A Study on Effectiveness and Outcomes of Educational Inhaler Technique Counselling in Respiratory Department by Clinical Pharmacist
}

\author{
Kavit Thakkar ${ }^{1, *}$, Rohan Patel', Rinchu Abraham ${ }^{1}$, Arti Shah $^{2}$, Hemrajsingh Rajput ${ }^{1}$, Vikas Chandrakar ${ }^{1}$ \\ 'Department of Pharmacy, Sumandeep Vidyapeeth (Deemed to be University), Waghodiya, Vadodara, Gujarat, INDIA. \\ ${ }^{2}$ Department of Respiratory Medicine, SBKS Medical institute and research center, Sumandeep Vidyapeeth (Deemed to be University), \\ Waghodiya, Vadodara, Gujarat, INDIA.
}

\begin{abstract}
Background: The correct inhalation technique is a crucial factor governing the efficiency of inhaled medication and is critical in ensuring optimal medication conveyance to the lungs. It is imperative to use the inhaler properly and to have sufficient knowledge, so we conducted this study to assess technique and provide education on Inhaler techniques in patients with respiratory disease. Materials and Methods: A Cross-sectional interventional study was conducted at the Department of Respiratory Medicine, Dhiraj Hospital, Vadodara, from October 2019 to March 2020. The inhalation technique was evaluated by specific checklist (NHS Liverpool Clinical Commissioning Group- inhaler device checklist). Patients having incorrect inhaler techniques were counselled along with physical demonstration of the proper inhaler technique. A pre-and post-intervention score was compared to evaluate the benefit of the intervention. Results: A total of 120 patients were enrolled in the study. Before counseling, $11.67 \%, 58.33 \%$, and $30 \%$ of patients had poor, moderate, and good inhaler technique, respectively, while post counseling, $87.50 \%, 12.50 \%$, and $0 \%$ had good, moderate, and poor inhaler technique, respectively. Pearson correlation coefficient $(r)$ value of 0.6686 depicts strong positive correlation between pre-and post-intervention mean scores with significant $p$-value. Literacy and age showed considerable impact on inhaler techniques. Conclusion: Overall, the majority of patients had erroneous inhaler technique, however after counseling a dramatic surge in the number of patients having correct inhaler technique was beheld, which suggests that clinical pharmacist's frequent counselling is indispensable and can improve efficacy and therapeutic outcomes.
\end{abstract}

Key words: Asthma, COPD, Respiratory, Inhaler, Intervention, NHS checklist.

\section{INTRODUCTION}

Respiratory disease is a type of illness that affects the lungs and other parts of the respiratory system. It mainly affects the respiratory tract with the pleurae, bronchioles, pleural cavity, bronchi, alveoli, and muscles of respiration. Around 65 million people have moderate to severe chronic obstructive pulmonary disease (COPD), out of which nearly 3 million die every year. The prevalence of asthma is around 334 million making it the most common chronic disease. For a long time, acute lower respiratory tract infection has been among the top three causes of death. While tuberculosis affects 10.4 million people, from which 1.4 million people die every year. ${ }^{1,2}$ The inhaler is a widely used medical device that delivers the drug directly into the body via the lungs and plays a significant role in the management of respiratory diseases, mainly asthma and COPD. ${ }^{3}$

The technique of inhalation is a crucial factor governing the efficiency of inhaled medication. Correct inhalation technique is critical in ensuring optimal medication
DOI: 10.5530/ijopp.14.4.52

Address for correspondence: Dr. Kavit Thakkar, Pharm.D Department of Pharmacy, Sumandeep Vidyapeeth (Deemed to be University), Waghodiya-391760, Vadodara, Gujarat, INDIA.

Phone no: +91-940-953-1621 Email id: kavitthakkar9@gmail. com

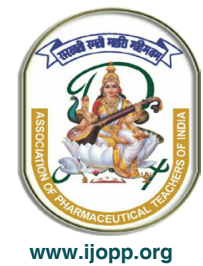


conveyance to the lungs, and thereby its efficacy. It is imperative to use the inhaler properly and to have adequate knowledge regarding the use of inhalers. By implementing the proper technique, the drug goes deep down the lungs and reaches the smaller airways. Patients often make an error while using the inhaler, like not holding the inhaler in the proper position, not breathing out properly, not shaking the inhaler before use, not breathing in properly, and not closing the inhaler after use. ${ }^{3,4}$ This increases the cost of treatment, increases medication wastage, decreases drug delivery to lungs, and affects disease control. Also, during the maintenance therapy, that may increase the risk of hospitalization for COPD or asthma patients. Incorrect inhaler technique, while using inhaled corticosteroids, usually elevates the chances of adverse effects like dysphonia and oral candidiasis. Checking and correcting the inhaler technique can improve outcomes and treat disease. ${ }^{5,6}$ However, the erroneous inhalation technique is usual in chronic airflow obstruction patients, and hence, appropriate training is essential for all these patients to ensure optimal therapy.

Previous studies have reported a high rate of inadequate inhalation techniques. In one of the studies, 120 patients had enrolled, from which 60 patients were of asthma and COPD each, where $94.2 \%$ of patients made at least one mistake in using an inhaler. ${ }^{7}$ A cross-sectional study conducted by Yusuf Aydemir et al. shows that before training, the rate of correct usage of dry powder inhalers (DPI) was $58.9 \%$ and $31.1 \%$ for pressurized metereddose inhalers (pMDI), which increased to $92.1 \%$ for dry powder inhaler and $45.2 \%$ for pMDI after the training. But even after the face-to-face training, incorrect usage was continued by the older patients and the patients using the pMDI device. ${ }^{8}$ Therefore, an evaluation of the inhaler technique and appropriate training is necessary for these patients, as a significant proportion of patients have incorrect inhaler techniques.

\section{MATERIALS AND METHODS}

\section{Study Design and Ethical Approval}

A Cross-sectional interventional study was conducted at the Department of Respiratory Medicine, Dhiraj Hospital, Pipariya, Vadodara. It was initiated after getting ethical approval from the Sumandeep Vidyapeeth Institutional Ethics Committee (SVIEC NO: SVIEC/ ON/Phar/BNPG18/D19037). It was a single-group pre-post interventional study designed to analyze the upsides of clinical pharmacist intervention on the current status of the inhaler technique. The intervention includes one-to-one education on an inhaler and practical demonstration by three Pharm.D final year students (Doctor of Pharmacy).

\section{Study criteria}

Source of subjects: The study was carried out in the Respiratory medicine Outpatient department of Dhiraj Hospital, Pipariya, Vadodara, Gujarat, India.

Inclusion criteria: A total of 120 patients who visited the outpatient department of the Respiratory medicine at Dhiraj Hospital of either gender, age $\geq 18$ years, prescribed by an inhaler, and willing to participate in the study were not included.

Exclusion criteria: While Unconscious, severely disabled patients, pediatric patients, critically ill patients, patients using nebulizers, and who had difficulty in communication were not included in the study.

Sample size: A total of 120 patients attending Respiratory medicine Outpatient department of Dhiraj Hospital, Pipariya, Vadodara, Gujarat, India, were included in the study.

The sample size was calculated under the guidance of a Biostatistician of the Dhiraj Hospital, Vadodara, using the below-mentioned formula.

$$
\mathrm{n}=\frac{\mathrm{Z}^{2} \cdot \mathrm{P}(1-\mathrm{P})}{\mathrm{d}^{2}}
$$

where, $\mathrm{n}=$ sample size, $\mathrm{P}=$ prevalence, $\mathrm{Z}=$ Level of confidence and $\mathrm{d}=$ Precision.

Study duration: The duration of the study was six months. (October 2019 to March 2020)

\section{Data collection, technique assessment, and intervention}

Before participation in the study, patients were provided with the patient information sheet and written informed consents were obtained. All the sociodemographic and clinical information such as gender, age, education, diagnosis, prescribed drugs, type of inhaler and duration of inhaler use, and others were collected from patients and assured that all information and records would be kept confidential. The inhalation technique was evaluated by a specific checklist (NHS Liverpool Clinical Commissioning Group- inhaler device checklist). As per the NHS Liverpool Clinical Commissioning Groupinhaler device checklist, each right step was assigned with one point, and each wrong or skipped step was assigned with zero points. The patients having incorrect inhaler 
techniques were counselled, along with the physical demonstration of the proper inhaler technique. The patients were instructed to clear any of their doubts and questions for additional explanation. A re-evaluation of the inhalation technique was done using the same scoring system.

\section{Statistical analysis}

All the gathered data were transcribed into Microsoft Excel, and data were cleaned by double-checking with the source data, and all out of the range or incorrect values were cross-verified and corrected. While the descriptive analysis was done using Microsoft office excel with Students paired $t$-test and Pearson correlation to analyze the advantages of clinical pharmacist's intervention (comparison of pre-and post-intervention scores). A $p$-value of $<0.05$ was considered significant.

\section{RESULTS}

A total of 120 patients were enrolled in the study from the OPD of the respiratory department of Dhiraj Hospital. The age of the patients varies from 18-76 years, with a mean age of $46.8 \pm 14.51$ (Mean \pm SD). Subjects were divided into three age bundles, the young age group (18-37 years) consists of 30\% patients, the middle age group (38-57 years) consists of $42.5 \%$ patients, and the old age group (58-77 years) consists of $27.5 \%$ patients. Out of the total subjects enrolled, $54.17 \%$ were male, while $45.83 \%$ were female patients. In terms of literacy, $35.83 \%$ of patients were uneducated, followed by secondary education (25\%), primary education (24.17\%), and higher education (15\%).

Bifurcating the patients according to the kind of inhaler they used, $39.17 \%$ of patients were utilizing a metered-dose inhaler (MDI), around one-third of patients $(34.17 \%)$ were using metered-dose inhaler + spacer (MDI+S), and $26.67 \%$ of patients were using dry powder inhaler (DPI). Duration of inhaler use shows that patients utilizing inhalers since under one year were $40 \%$, followed $1-2$ years $(25.83 \%)$, more than 2 to 4 years $(25 \%)$, and over four years (9.17\%). Commonly used drugs using inhalers were a combination of budesonide + formoterol (48.33\%). Disease distribution shows that $39.17 \%$ were diagnosed with asthma, $26.67 \%$ with COPD, a one-fifth fraction (20\%) with tuberculosis, $6.67 \%$ with lower respiratory tract infection (LRTI), and $7.50 \%$ were diagnosed with other disease conditions. Associated comorbidities were found in $40.83 \%$ of patients, while 59.17\% didn't have any comorbidities.
According to Table 1, the mean score of MDI-using patients was highest among all three inhalers. The mean score of MDI + S using patients before counseling was 4.87 that increased to 6.3 , and the mean score of DPI using patients before intervention was 4.78 , which surged up to 6.38 after the intervention. The p-value of less than 0.0001 was statistically significant. The Pearson correlation coefficient $(r)$ values show a strong positive linear relationship between the pre-and postintervention mean score of MDI, MDI + S, and DPI. A value of $r=0.6686$ for the overall score of 120 patients shows a strong positive correlation between pre-and post-intervention mean scores. The significant rise in the overall mean score after counseling justifies the effect of clinical pharmacist-based educational intervention on the correctness of the inhaler technique.

Moreover, to evaluate the inhalation technique, the NHS Liverpool Clinical Commissioning Group inhaler device checklist was used. The inhalation technique of MDI patients (Table 2) was assessed, before the counseling majority of the MDI patients made an error in step 6 , i.e., holding the breath for $10 \mathrm{sec}$ before exhaling the air, and step 3, i.e., to exhale the air before starting the inhalation. In contrast, after the intervention, the ratio of patients accurately performing steps 6 and 3 surged up to $76.60 \%$ and $95.74 \%$, respectively. A statistically significant $p$-value $(0.0015)$ claims that there's a pronounced improvement in the MDI technique of patients after educating them.

In the dry powder inhaler (Table 3), before intervention majority of the DPI patients made an error in step 5, i.e., to breathe out and place lips around the mouthpiece tightly to form a good seal and breathe in deeply through the device and step 6, i.e., to hold the breath for 5-10 sec and then breathe out. On the other side after the intervention, the percentage of patients accurately performing steps 5 and 6 raised to $90.63 \%$ and $78.13 \%$, respectively, with a statistically significant p-value of 0.0411 . It shows a drastic rise in the proportion of patients performing the correct DPI technique after the intervention.

\begin{tabular}{|c|c|c|c|c|}
\hline \multirow{2}{*}{$\begin{array}{l}\text { Type of } \\
\text { Inhaler }\end{array}$} & \multicolumn{2}{|c|}{ Mean Score (out of 7) } & \multirow[b]{2}{*}{$P$ value } & \multirow[b]{2}{*}{$r$} \\
\hline & $\begin{array}{c}\text { Pre- } \\
\text { intervention }\end{array}$ & $\begin{array}{c}\text { Post- } \\
\text { Intervention }\end{array}$ & & \\
\hline MDI & 5.14 & 6.5 & $0.00001^{*}$ & $0.6533^{*}$ \\
\hline $\begin{array}{c}\text { MDI + } \\
\text { SPACER }\end{array}$ & 4.87 & 6.3 & $0.00001^{*}$ & $0.7065^{*}$ \\
\hline DPI & 4.78 & 6.38 & $0.00001^{*}$ & $0.6237^{*}$ \\
\hline
\end{tabular}

$r=$ Pearson correlation coefficient, *significant 
Table 2: MDI checklist with pre- and post-counselling score comparison.

\begin{tabular}{|c|c|c|c|}
\hline MDI Checklist & $\begin{array}{l}\text { Pre-Counselling } \\
\text { score, Patients, } \\
\text { N (\%) }\end{array}$ & $\begin{array}{c}\text { Post-Counselling } \\
\text { score, Patients, } \\
\text { N (\%) }\end{array}$ & $\begin{array}{c}\text { Students } \\
\text { Paired t-test. } \\
\text { ( } P \text { Value })\end{array}$ \\
\hline Step-1. Remove cap on the mouthpiece & $42(89.36)$ & $46(97.87)$ & \\
\hline Step-2. Hold inhaler upright and shake well & $41(87.23)$ & $47(100.00)$ & \\
\hline Step-3. Breathe out gently as far as comfortable & $28(59.57)$ & $45(95.74)$ & \\
\hline $\begin{array}{l}\text { Step-4. Put mouthpiece in your mouth and close lips around it to form a } \\
\text { good seal }\end{array}$ & $36(76.60)$ & $43(91.49)$ & $0.0015^{*}$ \\
\hline $\begin{array}{l}\text { Step-5. Start to breathe in slowly through your mouth and at the same } \\
\text { time press down firmly on the canister }\end{array}$ & $36(76.60)$ & $46(97.87)$ & \\
\hline $\begin{array}{l}\text { Step-6. Hold your breath for up to } 10 \text { sec then remove inhaler from your } \\
\text { mouth }\end{array}$ & $21(44.68)$ & $36(76.60)$ & \\
\hline $\begin{array}{l}\text { Step-7. Breathe out gently away from mouthpiece, replace cap, and } \\
\text { Repeat steps 3-6 if } 2 \text { nd dose is required, wait } 1 \text { min between puffs }\end{array}$ & $32(68.09)$ & $32(89.36)$ & \\
\hline
\end{tabular}

*Significant, \%= percentage of patients performing step correctly, $N=$ number of patients performing step correctly.

Table 3: DPI checklist with pre- and post-counselling score comparison.

\begin{tabular}{|c|c|c|c|}
\hline DPI Checklist & $\begin{array}{l}\text { Pre-Counselling } \\
\text { score, Patients, } \\
\text { N (\%) }\end{array}$ & $\begin{array}{l}\text { Post- } \\
\text { Counselling } \\
\text { score, Patients, } \\
\mathbf{N}(\%) \\
\end{array}$ & $\begin{array}{l}\text { Students } \\
\text { Paired t-test. } \\
\text { ( } P \text { Value })\end{array}$ \\
\hline Step-1. Remove cap and open device by tilting mouthpiece backwards & $30(93.75)$ & $32(100.00)$ & \\
\hline $\begin{array}{l}\text { Step-2. Remove one capsule from blister packaging and place it in chamber } \\
\text { at the base of device. }\end{array}$ & $31(96.88)$ & $32(100.00)$ & \\
\hline $\begin{array}{l}\text { Step-3. Close device by pulling mouthpiece forwards until it clicks into place } \\
\text { over capsule chamber. }\end{array}$ & $30(93.75)$ & $31(96.88)$ & \\
\hline $\begin{array}{c}\text { Step-4. Press two side buttons of device inwards to pierce capsule, and then } \\
\text { release them. }\end{array}$ & $29(90.63)$ & $32(100.00)$ & $0.0411^{*}$ \\
\hline $\begin{array}{l}\text { Step-5. Breathe out and then place your lips around mouthpiece and breathe } \\
\text { in as deeply as you can through device - you will hear a whirring noise as } \\
\text { you do this. }\end{array}$ & $11(34.38)$ & $29(90.63)$ & \\
\hline $\begin{array}{l}\text { Step-6. Hold your breath for } 5-10 \text { sec and then breathe out. Open the device } \\
\text { and check to make sure the capsule is empty. If so, remove the empty } \\
\text { capsule. If there is still some powder in the capsule, close the device again } \\
\text { and repeat the previous step to breathe in the rest of the powder }\end{array}$ & $9(28.13)$ & $25(78.13)$ & \\
\hline Step-7. Rinse your mouth with water. & $13(40.63)$ & $22(68.75)$ & \\
\hline
\end{tabular}

*Significant, \%= percentage of patients performing step correctly, $N=$ number of patients performing step correctly.

Furthermore, in MDI+S (Table 4), before counseling majority of the patients made a mistake in step 5, i.e., to inhale the air gently and deeply, then hold the breath for about $10 \mathrm{sec}$ and step 3, i.e., breathe out slowly comfortably, where only $51.22 \%$ and $53.66 \%$ could perform step 5 and 3 accurately respectively. After the intervention, the ratio of patients accurately performing steps 5 and 3 increased to $75.61 \%$ and $90.24 \%$, respectively, with a statistically significant p-value of 0.0019 .

According to the NHS Liverpool Clinical Commissioning Group - the inhaler device checklist, the inhaler technique was classified into three groups, based on the score obtained out of 7 by an individual patient. Patients who achieved a score between 0-3 had a poor inhaler technique, which indicates that they performed at least 4 out of 7 steps incorrectly. Similarly, for the score of 4-5 points, the patient had a moderate inhaler technique and performing at least two steps incorrectly. The patients who scored 6 or 7 points had a good inhaler technique. The Table 5 shows that before the intervention, 11.67\% of patients had poor inhaler technique, 58.33\% had moderate inhaler technique, and only $30 \%$ had good inhaler technique. On the other side, after providing counseling to the patients who performed one or more incorrect steps and re-evaluating their inhaler technique, a significant rise has been noted in the number of patients having a good inhaler technique. Post-intervention majority of the patients, i.e., $87.50 \%$, had a good inhaler technique, and only $12.50 \%$ had a 
Table 4: MDI+S checklist with pre- and post-counselling score comparison.

\begin{tabular}{|c|c|c|c|}
\hline MDI + spacer Checklist & $\begin{array}{l}\text { Pre-Counselling } \\
\text { score, Patients, } \\
\text { N (\%) }\end{array}$ & $\begin{array}{l}\text { Post-Counselling } \\
\text { score, Patients, } \\
\text { N (\%) }\end{array}$ & $\begin{array}{l}\text { Students } \\
\text { Paired t-test. } \\
\text { (P Value) }\end{array}$ \\
\hline Step-1. Remove cap, hold inhaler upright and shake well & $32(78.05)$ & $41(100.00)$ & \\
\hline Step-2. Insert inhaler upright into the hole in the spacer & $40(97.56)$ & $41(100.00)$ & \\
\hline Step-3. Breathe out gently as far as comfortable & $22(53.66)$ & $37(90.24)$ & \\
\hline $\begin{array}{l}\text { Step-4. Put mouthpiece on spacer between teeth without biting and close } \\
\text { lips to form a good seal }\end{array}$ & $31(75.61)$ & $39(95.12)$ & $0.0019^{*}$ \\
\hline $\begin{array}{l}\text { Step-5. Hold spacer level and press down firmly on the canister to release } \\
\text { one puff: Breathe in slowly and deeply then hold breath for about } 10 \mathrm{sec} \text {. } \\
\text { Breathe in and out normally for } 4 \text { breaths. }\end{array}$ & $21(51.22)$ & $31(75.61)$ & \\
\hline $\begin{array}{l}\text { Step-6. Remove spacer from mouth and breathe out gently. Repeat steps } \\
3-6 \text { if } 2 \text { nd dose is required. You need to shake the canister again and } \\
\text { ideally wait } 1 \text { min between puffs }\end{array}$ & $27(65.85)$ & $35(85.37)$ & \\
\hline $\begin{array}{l}\text { Step-7. Remove inhaler from spacer, and replace cap. Check patient } \\
\text { knows how to clean spacer each month (if relevant) }\end{array}$ & $27(65.85)$ & $34(82.93)$ & \\
\hline
\end{tabular}

*Significant, \%= percentage of patients performing step correctly, $N=$ number of patients performing step correctly.

Table 5: Standard of correct inhaler technique, before and after counselling.

\begin{tabular}{ccccccc} 
& \multicolumn{3}{c}{ Pre-counselling } & \multicolumn{3}{c}{ Post-counselling } \\
\cline { 2 - 7 } Type of Inhaler & Poor technique & $\begin{array}{c}\text { Moderate } \\
\text { technique }\end{array}$ & Good technique & Poor technique & $\begin{array}{c}\text { Moderate } \\
\text { technique }\end{array}$ & Good technique \\
\cline { 2 - 7 } & $\%(\mathbf{n})$ & $\%(\mathbf{n})$ & $\%(\mathbf{n})$ & $\%(\mathbf{n})$ & $\%(\mathbf{n})$ & $\%(\mathbf{n})$ \\
\hline MDI (47) & $8.51(4)$ & $55.32(26)$ & $36.17(17)$ & $0.00(0)$ & $8.51(4)$ & $91.49(43)$ \\
MDI+S (41) & $17.07(7)$ & $58.54(24)$ & $24.39(10)$ & $0.00(0)$ & $17.07(7)$ & $82.93(34)$ \\
DPI (32) & $9.38(3)$ & $62.50(20)$ & $28.13(9)$ & $0.00(0)$ & $12.50(4)$ & $87.50(28)$ \\
Total (120) & $11.67(14)$ & $58.33(70)$ & $30.00(36)$ & $0.00(0)$ & $12.50(15)$ & $87.50(105)$ \\
\hline
\end{tabular}

$\%=$ Percentage of patients in respective group.

$N=$ Number of patients in respective group.

moderate inhaler technique.

Literacy had shown considerable impact on the inhaler technique. Before counseling, in the higher education group, $67 \%$ of patients had good inhaler technique, while none had poor inhaler technique. Around 21\% of the primary school group and about $14 \%$ of the uneducated group patients had poor inhaler technique before the counseling. However, after bestowing the education to the individuals making an error, an apparent rise in the ratio of the patients having proper inhaler technique has been witnessed. The $100 \%$ of the higher education group, $93.33 \%$ of the secondary education group, $82.76 \%$ of the primary education group, and $81.40 \%$ of the uneducated group patients had a good inhaler technique. It shows that education somehow affects inhaler technique, and there's a sound difference between the percentage of patients having good inhaler technique pre-and post-intervention.

The elderly patient's inhaler technique was more compromised compared to other age group patients.
Before counseling, in the poor inhaler technique group, the maximum number of patients were of the old age group. In contrast, in a good inhaler technique group, a maximum number of patients were of the young age group. Later providing the proper education, a significant rise in the old age patients performing the correct inhaler technique was noted (from 27.27\% to $84.85 \%$ ), also quite similar to that has been witnessed for the young and middle age group. It shows that proper and frequent counseling for the inhaler technique is beneficial to patients.

\section{DISCUSSION}

The inaccurate technique of inhaler use is often an Achilles heel in the treatment of pulmonary disease. A cross-sectional interventional study to evaluate the knowledge of inhaler use was conducted among respiratory disease patients. Moreover, an inhaler device is an invaluable tool to treat respiratory disease. The inhaled medications can reduce airway inflammation, relieve shortness of breath, or improve airflow. The 
quantity of medicine that reaches the desired organ is vital for improved efficacy in the treatment, which depends on the technique of inhalation, type of inhalers, and compliance with inhalers. So, proper technique improves disease outcomes and the quality of life of patients. ${ }^{9,10}$

There are two widely used methods to provide structured education regarding inhaler use- one, to bestow the actual physical demonstration of the device and provide printed material/flyer enunciating the pictures or text explaining the method of inhaler use. We carried out this study by providing a physical demonstration of the device to the patients. The result shows a drastic difference between the pre-and post-intervention score, justifying the effect of counseling by the clinical pharmacist, who has a sound role in the healthcare setting. It bears witness, frequent counseling, and proper demonstration of the device using the standard checklist significantly reduces the error. ${ }^{11-14}$

According to the NHS Liverpool checklist, each inhaler has its specific steps to be followed during an inhalation. This checklist has a 7-step inhalation technique mentioned for each inhaler, where each step carries one point. We witnessed that more than one fraction of the population had a moderate inhaler technique, and $30 \%$ of patients had good inhaler techniques before counseling. However, the ratio significantly surged up post counseling. After providing counseling, the patients were again intervened and noted that a higher proportion of patients $(87.50 \%)$ had a good inhaler technique, $12.50 \%$ had a moderate inhaler technique, while none had poor inhaler technique. The proper inhalation technique is a prime requisite to control the disease progression, and it is required to educate patients regarding the correct inhalation technique. ${ }^{15,16}$ Our single session of clinical pharmacist intervention corrected the inhaler technique in $70 \%$ of patients. In contrast, a previous study by Shrestha et al. explains that the method of an actual representation of correct inhalation technique along with video recordings helped only $33.6 \%$ in the counseled patients, ${ }^{17}$ recommending that the demonstration and training after verbal instruction might be a superior policy in elevating the technique of inhaler use. The study conducted by Sen $e t$ al. ${ }^{18}$ shows that around two-thirds (65.5\%) of patients using MDI had proper inhalation techniques. In this study, before the intervention, only $36.17 \%$ of patients had the correct inhaler technique. However, it significantly raised to a higher proportion after counseling. In metered-dose inhaler + spacer, $58.54 \%$ and $24.39 \%$ of patients had moderate and good inhaler technique respectively before counseling, later after counseling, $82.39 \%$ of patients had a good inhaler technique. A study conducted by G.P. Jolly et al. ${ }^{19}$ depicts those common errors observed in his study were in steps "omitting to exhale before inhaling" and "not holding the breath for $10 \mathrm{sec}$ after inhaling", we noted similar errors in patients using MDI and MDI along with spacer. Patients made errors in steps like holding breath for $10 \mathrm{sec}$ after inhaling the medication and breathing out gently before initiating inhalation. Also, maximum exhalation or up to the comfortable point before inhalation can decrease the proportion of air present in the airways, which will increase the space available for air. It results in maximizing the efficacy to carry the molecule to a targeted site. Hence, proper emphasis on these two steps is necessary while using the device. ${ }^{20,21}$

Furthermore, in patients using DPI, 28.13\% had good inhaler techniques before counseling, and it surged up to $87.5 \%$ after counseling. Patients using DPI had an error in breathing out and placing lips around the mouthpiece tightly to form a good seal and breathe in. A large fraction of patients were unable to make a good seal around the mouthpiece of the inhaler. It is essential to produce adequate inspiratory flow and humidity sensitivity so that condensation on the mouthpiece, leading to clumping of the drug, and also severely impaired disaggregation do not occur. Lack of proper exhalation before inhalation was the most common error in all three types of inhalers. Ramesh Sharma Poudel et al. suggests that repetitive educational intervention enhances the ability of patients to adequately use the inhaler, ${ }^{22}$ where repetitive counseling will lead to improved inhalation technique and improved outcomes and disease control.

We observed a clear impact of literacy on inhaler technique. A study conducted by Jalpa Suthar et al. and Alpesh Chauhan et al. shows that educated people are more prone to understand inhaler techniques when compared to uneducated people. ${ }^{23}$ While we witnessed a similar trend in our study, literate patients made considerably fewer errors when compared to illiterate patients. Educated people can read the leaflets and brochures available with the inhaler, which is beneficial for proper inhalation techniques. Also, they have more awareness about the effect of correct inhalation techniques to manage the disease. Consumer medicine information leaflet, together with the inhaler, might not be fruitful to uneducated patients. ${ }^{24}$ Post-intervention, more than $80 \%$ of patients of all the groups as per education status showed improvement.

Elderly patients had more erroneous inhaler techniques 
compared to young and middle-aged patients. Older people may forget some steps or the existence of other comorbidities, which makes it difficult for them to use the inhalers properly. But frequent and correct counseling regarding the inhaler techniques can be very favorable in such conditions. A large fraction of a younger group of patients had good inhalation techniques before the counseling, which depicts that age plays a crucial role in proper inhaler technique. Association of a post-counseling score and age suggests that frequent reinforcement and re-assessment are necessary for older patients.

Our study had few limitations that may affect the generality and precision of the results. The post counseling assessment of the inhalation technique was repeated after $10 \mathrm{~min}$; hence, the efficacy of the counseling for a prolonged period is unpredictable. Moreover, all the subjects were enrolled from only one hospital, which might affect the accuracy of these results. However, our findings have high practical relevance. Implementation of such a service in every healthcare setting may enhance the inhalation technique in respiratory disease patients. Furthermore, our study has successfully estimated the benefit of clinical pharmacist intervention on the inhaler technique in respiratory disease patients in Vadodara, India.

\section{CONCLUSION}

Overall, this found a significant prevalence of incorrect inhaler usage, a small fraction of subjects could perform all the essential steps of the inhalation technique properly. Post counseling, there was an increment in the ratio of patients using the inhaler correctly. A single counseling session with a physical demonstration of inhaler techniques was beneficial and showed improvement in the inhaler techniques. A single session counseling might not be enough for older and uneducated patients, so it is imperative to follow up and reassess the inhaler techniques. Clinical Pharmacist intervention can improve patient's knowledge about inhaler techniques and demonstrate the steps of the inhaler. So, frequent counseling is essential to enhance efficacy, adherence, and better outcomes in respiratory disease patients.

\section{ACKNOWLEDGEMENT}

We express our sincere gratitude to the Respiratory Outpatient Department of Dhiraj Hospital for their help and support throughout the study period. Also, grateful to our guides and colleagues for continuous motivation and support and patients who participated in the study.

\section{CONFLICT OF INTEREST}

The authors declare no conflict of interest.

\section{ABBREVIATIONS}

NHS: National Health Service; COPD: Chronic Obstructive Pulmonary disease; MDI: Metered Dose Inhaler; DPI: Dry Powder Inhaler; MDI + S: Metered dose inhaler + Spacer; pMDI: Pressurised Metered Dose Inhaler; OPD: Outpatient Department.

\section{REFERENCES}

1. Fink JB, Rubin BK. Problems with inhaler use: a call for improved clinician and patient education. Respir Care. 2005;50(10):1360-74; discussion 1374. PMID 16185371.

2. GBD 2015 Mortality and Causes of Death Collaborators Global, regional, and national life expectancy, all-cause mortality, and cause-specific mortality for 249 causes of death, 1980-2015: a systematic analysis for the Global Burden of Disease Study 2015. Lancet. 2016;388(10053):1459-544. doi: 10.1016/S01406736(16)31012-1. PMID 27733281

3. Virchow JC, Crompton GK, Dal Negro R, Pedersen S, Magnan A, Seidenberg J, Barnes PJ. Importance of inhaler devices in the management of airway disease. Respir Med. 2008;102(1):10-9. doi: 10.1016/j.rmed.2007.07.031, PMID 17923402.

4. Van Der Palen J, Thomas M, Chrystyn H, Sharma RK, Van Der Valk PD. A randomised open-label cross-over study of inhaler errors, preference and time to achieve correct inhaler use in patients with COPD or asthma: comparison of ELLIPTA with other inhaler devices. NPJ primary care respiratory medicine. 2016 24;26(1):1-8.

5. Pun S, Prasad GK, Bharati L Assessment Of Inhalation Techniques In Copd Patients Using Metered-Dose Inhaler And Rotahaler At A Tertiary Care Hospital In Nepal. Int Res J Pharm;6(5):288-93. doi: 10.7897/2230-8407.06563.

6. van der Palen J, Klein JJ, Kerkhoff AH, van Herwaarden CL. Evaluation of the effectiveness of four different inhalers in patients with chronic obstructive pulmonary disease. Thorax. 1995;50(11):1183-7. doi: 10.1136/thx.50.11.1183, PMID 8553275

7. Souza ML, Meneghini AC, Ferraz E, Vianna EO, Borges MC. Knowledge of and technique for using inhalation devices among asthma patients and COPD patients. J Bras Pneumol. 2009;35(9):824-31. doi: 10.1590/s180637132009000900002 , PMID 19820807.

8. Aydemir Y. Assessment of the factors affecting the failure to use inhaler devices before and after training. Respir Med. 2015;109(4):451-8. doi: 10.1016/j. rmed.2015.02.011, PMID 25771037.

9. Ravikumar P, Raghavendra MK, Priyadarshini GB Evaluation of inhalational techniques of pressurized metered-dose inhaler with spacer in asthma patients. Lung India. 2018;35(3):279-80. doi: 10.4103/lungindia.lungindia_211_17. PMID 29697097.

10. Abegaz TM, Shegena EA, Gessie NF, Gebreyohannes EA, Seid MA. Barriers to and competency with the use of metered dose inhaler and its impact on disease control among adult asthmatic patients in Ethiopia. BMC Pulm Med. 2020;20(1):48. doi: 10.1186/s12890-020-1081-6, PMID 32085726.

11. Crane MA, Jenkins CR, Goeman DP, Douglass JA. Inhaler device technique can be improved in older adults through tailored education: findings from a randomised controlled trial. npj Prim Care Respir Med. 2014;24:14034. doi: 10.1038/npjpcrm.2014.34, PMID 25188403.

12. Harnett CM, Hunt EB, Bowen BR, O'Connell OJ, Edgeworth DM, Mitchell P, Eustace JA, Henry MT, Kennedy MP, Plant BJ, Murphy DM A study to assess inhaler technique and its potential impact on asthma control in 
patients attending an asthma clinic. J Asthma. 2014;51(4):440-5. doi: 10.3109/02770903.2013.876650

13. Plaza V, Giner J, Calle M, Rytilä P, Campo C, Ribó P, Valero A. Impact of patient satisfaction with his or her inhaler on adherence and asthma control. Allergy Asthma Proc. 2018;39(6):437-44. doi: 10.2500/aap.2018.39.4183, PMID 30336791.

14. Lenney J, Innes JA, Crompton GK. Inappropriate inhaler use: assessment of use and patient preference of seven inhalation devices. EDICI. Respir Med. 2000;94(5):496-500. doi: 10.1053/rmed.1999.0767, PMID 10868714.

15. Chorão P, Pereira AM, Fonseca JA. Inhaler devices in asthma and COPD an assessment of inhaler technique and patient preferences. Respir Med. 2014;108(7):968-75. doi: 10.1016/j.rmed.2014.04.019.

16. Sodhi MK. Incorrect inhaler techniques in Western India: still a common problem. Int J Res Med Sci. 2017;5(8):3461. doi: 10.18203/2320-6012.jirms20173541.

17. Shrestha S, Sapkota B, Ghimirey A, Shakya R, et al. Impact of counselling in inhalation technique (rotahaler) in chronic obstructive pulmonary disease patients. Int J Pharm. 2013;3(3):442-9.

18. Şen E, Gönüllü U, Ekici Z, Kurşun N, et al. Assessment of inhaler technique and treatment compliance of hospitalized patients and outpatients in a university hospital. Ank Univ Tıp Fak Mecmuası. 2006;59:1-6.
19. Jolly GP, Mohan A, Guleria R, Poulose R, George J. Evaluation of Metered Dose Inhaler Use Technique and Response to Educational Training. Indian J Chest Dis Allied Sci. 2015;57(1):17-20. PMID 26410977.

20. Baay AS, et al.. Assessment of Inhalers Technique Proper Use for Patients with Chronic Respiratory Diseases in Primary and Secondary Clinics in Babylon City. Shammer NH. Asian J Pharm Clin Res. 2018;11(3).

21. Baby A, MP FN, Siby SM, et al. A study on the impact of clinical pharmacist initiated patient counselling in asthma and COPD patients. Asian $\mathrm{J}$ Pharm Health Sci. 2020;10(2).

22. Poudel RS, Piryani RM, Shrestha S, Prajapati A. Benefit of hospital pharmacy intervention on the current status of dry powder inhaler technique in patients with asthma and COPD: a study from the Central Development Region, Nepal. Integr Pharm Res Pract. 2017;6:7-13. doi: 10.2147/IPRP.S119202, PMID 29354546.

23. Suthar J, Patel ZA, Shelat B. Assessment of inhalation techniques in COPD and asthma patients using metered dose inhaler and rota-haler. Indian J Pharm Pract. 2019;12(4):217-24. doi: 10.5530/ijopp.12.4.47.

24. Arora P, Kumar L, Vohra V, et al. Evaluating the technique of using inhalation device in COPD and bronchial asthma patients. Respir Med. 2014;108(7):992-8. 